\title{
Pembangunan Sistem Pengurusan Program Secara Dalam Talian
}

\author{
Fawwaz Mohd Nasir*, Farah Wahidah Baharuddin, \\ Faakihah Mohammad Nizar, Nurhazirah Hazli
}

\author{
Jabatan Teknologi Maklumat, Pusat Pengajian Diploma, \\ Universiti Tun Hussein Onn Malaysia, 84600 Pagoh, Johor, MALAYSIA
}

DOI: https://doi.org/10.30880/mari.2020.01.01.003

Received 00 Month 2020; Accepted 01 Month 2020; Available online 02 Month 2020

\begin{abstract}
Abstarct: Currently, there is no specific platform to disseminate the student association programmes at Universiti Tun Hussein Onn Malaysia. Students have to rely on social media and instant messaging applications to disseminate programme information, thus resulting in the slow delivery of information or the information not being received by the target groups. Hence, the Programme Management System has been developed to make it easier for students to disseminate and obtain information on association programmes. This system is developed based on the waterfall model because the system requirements are clear and the model is easy to use. A total of 20 respondents participated in the user acceptance test and answered the questionnaire provided. The results of the feedback show that the majority of respondents agreed that this system helps and facilitates students in disseminating and obtaining information on the programme organized.
\end{abstract}

Abstrak: Pada masa ini, belum ada lagi satu platform khusus untuk menguar-uarkan program persatuan pelajar di Universiti Tun Hussein Onn Malaysia. Pelajar terpaksa bergantung media sosial dan aplikasi permesejan segera untuk menyebarkan maklumat program, sekali gus menyebabkan maklumat lambat atau tidak sampai kepada kumpulan sasar. Justeru, Sistem Pengurusan Program telah dibangunkan untuk memudahkan pelajar menguar-uarkan dan mendapatkan maklumat program persatuan. Sistem ini dibangunkan berdasarkan model air terjun kerana keperluan sistem adalah jelas dan model tersebut mudah digunakan. Seramai 20 responden telah menyertai ujian penerimaan pengguna dan menjawab soal selidik yang disediakan. Hasil daripada maklum balas, didapati majoriti responden bersetuju sistem ini membantu serta memudahkan pelajar menguar-uarkan dan mendapatkan maklumat program yang dianjurkan.

Kata kunci: model air terjun, reka bentuk web responsif, persatuan pelajar 


\section{Pendahuluan}

Penganjuran program-program persatuan dan fakulti oleh para pelajar merupakan satu lumrah di mana-mana institusi pengajian tinggi. Pelajar-pelajar di Universiti Tun Hussein Onn Malaysia (UTHM) juga tidak ketinggalan dalam menganjurkan pelbagai jenis program. Program-program ini kebiasaannya menyasarkan penyertaan dari bukan sahaja ahli persatuan tersebut, malah dari para pelajar lain. Bagi meningkatkan penyertaan para pelajar, ahli jawatankuasa penganjuran program (juga merupakan pelajar) akan menguar-uarkan maklumat program yang bakal dianjurkan. Proses penyebaran maklumat ini biasanya dilakukan menerusi media sosial serta aplikasi permesejan segera seperti Instagram dan WhatsApp. Proses ini dilihat kurang berkesan kerana ia terdedah kepada situasi di mana pelajar yang disasarkan, terlepas pandang tentang makluman penganjuran program. Perkara ini terjadi disebabkan ketiadaan platform khusus untuk menguar-uarkan maklumat program yang akan dianjurkan.

Oleh yang demikian, satu sistem yang dinamakan Sistem Pengurusan Program (SPP) telah dibangunkan bagi mengatasi masalah ini. Sistem ini berperanan untuk menguar-uarkan program yang akan dianjurkan oleh persatuan dan fakulti, disamping memudahkan para pelajar untuk mendapatkan maklumat mengenai sesebuah program. SPP dilihat dapat menjimatkan masa pelajar disebabkan penyampaian maklumat yang lebih teratur dan sistematik. Antara muka SPP direka dengan pendekatan reka bentuk web responsif, di mana antara muka sistem disesuaikan mengikut resolusi skrin peranti yang digunakan seperti komputer, tablet atau telefon pintar [1], [2]. Penggunaan pendekatan reka bentuk ini secara tidak langsung dapat mengoptimumkan penggunaan, selain memperkaya pengalaman pengguna [3].

Terdapat beberapa ciri-ciri utama di dalam SPP yang dibangunkan khusus untuk menyelesaikan masalah yang dinyatakan sebelum ini, serta untuk memudahkan pengurusan program dan para peserta. Ahli jawatankuasa (AJK) persatuan boleh mengisi maklumat program yang akan dianjurkan, melalui persatuan-persatuan yang didaftarkan di UTHM. Maklumat tersebut boleh dikemaskini sekiranya terdapat kesilapan atau perubahan butiran program. AJK juga boleh mengemaskini had penyertaan untuk sesuatu program yang bakal dijalankan. Selain itu, SPP dapat merekodkan pelajar-pelajar yang ingin menyertai program yang bakal dianjurkan. Seterusnya, kehadiran pelajar ke program yang dianjurkan dapat direkodkan melalui SPP, sekali gus menambahbaik rekod kehadiran pelajar secara manual yang bergantung kepada penggunaan kertas.

\section{Kajian Literasi}

Beberapa sistem sedia ada yang mempunyai fungsi yang lebih kurang sama telah dikaji untuk dijadikan panduan agar SPP dapat dibangunkan sebaik mungkin. Sistem sedia ada tersebut adalah Eventbrite, Sistem Maklumat Akademik Pelajar (SMAP) dan Edmodo. Ketiga-tiga sistem ini mempunyai kelebihan dan kekurangan tersendiri. Eventbrite misalnya, membolehkan para peserta mendapatkan tiket, mendaftar acara, mendapatkan maklumat acara dan menghantar jemputan e-mel [4], [5]. Walau bagaimanapun, acara hanya dapat diurus oleh pihak penganjur melalui satu akaun sahaja.

SMAP pula dibangunkan khusus untuk pelajar UTHM untuk memudahkan urusan berkaitan universiti. Urusan ini termasuklah membuat pembayaran yuran, melihat keputusan kursus serta memaparkan maklumat atau pengumuman dari pihak universiti. Walau bagaimanapun, SMAP tidak memaparkan kesemua program persatuan yang dianjurkan serta tiada kaedah pendaftaran secara dalam talian. Melihat kepada Edmodo pula, ia berkebolehan untuk mengingatkan pelajar tentang tugasan yang perlu dihantar sebelum tarikh akhir penghantaran, serta siaran (post) yang dibuat oleh guru mahupun rakan sekelas [6]. Tetapi, interaksi terus antara pelajar dengan pelajar lain tidak menyeluruh dan terhad kepada kelas yang disertai pelajar tersebut sahaja. Kelemahan tersebut merupakan penghalang dalam proses menguar-uarkan maklumat program kerana maklumat tersebut bukan sahaja hendak disampaikan kepada rakan sekelas, malah kepada rakan-rakan dari fakulti lain. 
Beberapa alat pembangunan perisian turut digunakan untuk merealisasikan SPP. Proses penyuntingan web misalnya, dilakukan menggunakan perisian Adobe Dreamweaver. Perisian ini memudahkan proses penyuntingan dengan fungsi what-you-see-is-what-you-get (WYSIWYG) melalui Live View, dan editor dengan fungsi-fungsi seperti runtuh kod (code collapsing), penyelesaian kod serta penonjolan sintaks (syntax highlighting) [7]. Perisian sumber terbuka XAMPP pula digunakan sebagai hos kepada SPP. Ia merupakan pakej perisian pelayan tempatan (local server atau localhost) yang terdiri daripada pelayan HTTP Apache, pangkalan data MariaDB serta pentafsir bahasa skrip (scripting language interpreter) PHP dan Perl [8]. Komponen-komponen ini digunakan di dalam kebanyakan pelayan langsung (live server). Ini secara tidak langsung, memudahkan proses pemindahan dari pelayan tempatan ke pelayan langsung [9].

\section{Metodologi}

Proses pembangunan SPP adalah berpaksikan kepada model air terjun (waterfall model). Model ini merangkumi lima fasa yang berturutan iaitu perancangan, analisis, reka bentuk, pembangunan dan implementasi, serta akhir sekali penyelenggaraan [10], [11]. Setiap fasa bergantung pada hasil fasa sebelumnya. Hubungan antara fasa-fasa tersebut adalah seperti di dalam Rajah 1.

Fasa perancangan yang merupakan fasa pertama adalah fasa yang amat penting dalam mana-mana proses pembangunan sistem kerana ini menentukan hala tuju pembangunan sistem. Fasa ini menekankan proses mengumpulkan maklumat dan mengenal pasti masalah-masalah yang menjadi pendorong untuk membangunkan satu sistem baharu. Sebagaimana yang dinyatakan sebelum ini, masalah utama yang menjadi pencetus pembangunan SPP adalah kesukaran menguar-uarkan dan mendapatkan maklumat penganjuran program persatuan secara efisien.

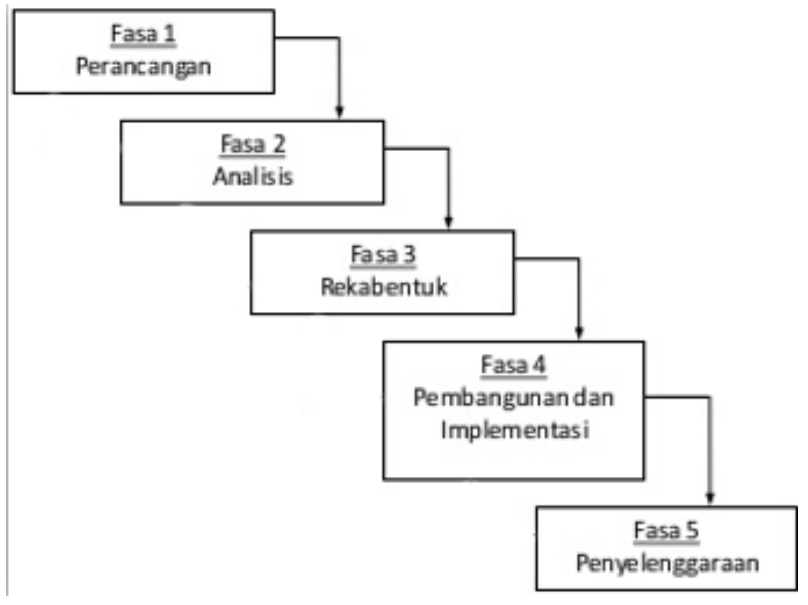

Rajah 1: Model Air Terjun

Setelah masalah dikenal pasti, analisis terperinci dibuat bagi mengetahui ciri-ciri yang perlu ada pada SPP. Ciri-ciri ini dikenal pasti agar sistem yang dibina nanti benar-benar menyelesaikan masalah yang telah dinyatakan pada fasa pertama tadi. Menerusi ciri-ciri ini juga, jenis-jenis data yang bakal digunakan dapat dikenal pasti selain menetapkan keperluan minimum perisian dan peranti yang akan digunakan SPP. Menerusi fasa ini, SPP sewajarnya dapat dipaparkan di pelbagai jenis peranti dengan resolusi skrin yang berbeza bagi mengoptimumkan penggunaan SPP. 
USER LOGIN

Username:

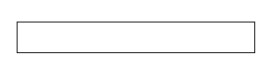

Password:

Rajah 2: Laman Utama

\begin{tabular}{|c|c|c|}
\hline SPP Logo & \multicolumn{2}{|c|}{ Navigation Button } \\
\hline $\begin{array}{l}\text { Menu Bar:- } \\
\text { - Upload } \\
\text { Program } \\
\text {-List of } \\
\text { Program } \\
\text { - Program } \\
\text { Organized } \\
\text { - Program } \\
\text { Registered }\end{array}$ & Feed of Program & $\begin{array}{l}\text { - Upcoming } \\
\text { Program } \\
\text { - Upcoming } \\
\text { Program } \\
\text { Registered }\end{array}$ \\
\hline
\end{tabular}

Rajah 3: Menu Utama

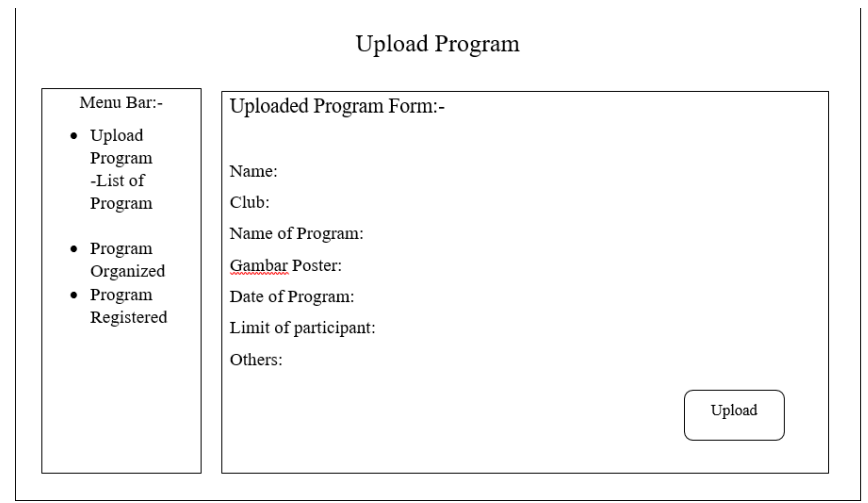

Rajah 4: Laman Memasukkan Program Baharu

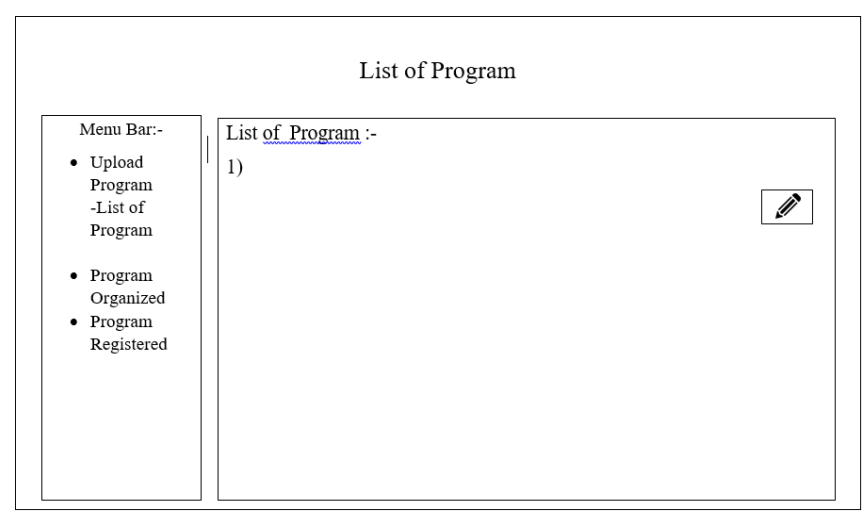

Rajah 5: Laman Senarai Program 
Berikutnya adalah fasa reka bentuk sistem. Semasa pelaksanaan fasa ini, antara muka sistem telah direka bentuk bagi menyusun unsur-unsur sesebuah laman web (lihat Rajah 2 hingga 5). Penyusunan unsur-unsur ini perlu mengambil kira jenis-jenis peranti yang mempunyai resolusi skrin berbeza. Ini dilakukan bagi mengelakkan satu unsur, contohnya butang, menjadi terlalu kecil apabila SPP dipaparkan pada skrin telefon pintar. Selain itu, reka bentuk logikal pangkalan data turut dirancang dengan membina rajah hubungan entiti (ERD). Langkah ini juga penting agar atribut-atribut dapat diletakkan pada entiti yang sewajarnya, selain mengenal pasti hubungan antara entiti (lihat Rajah 6).

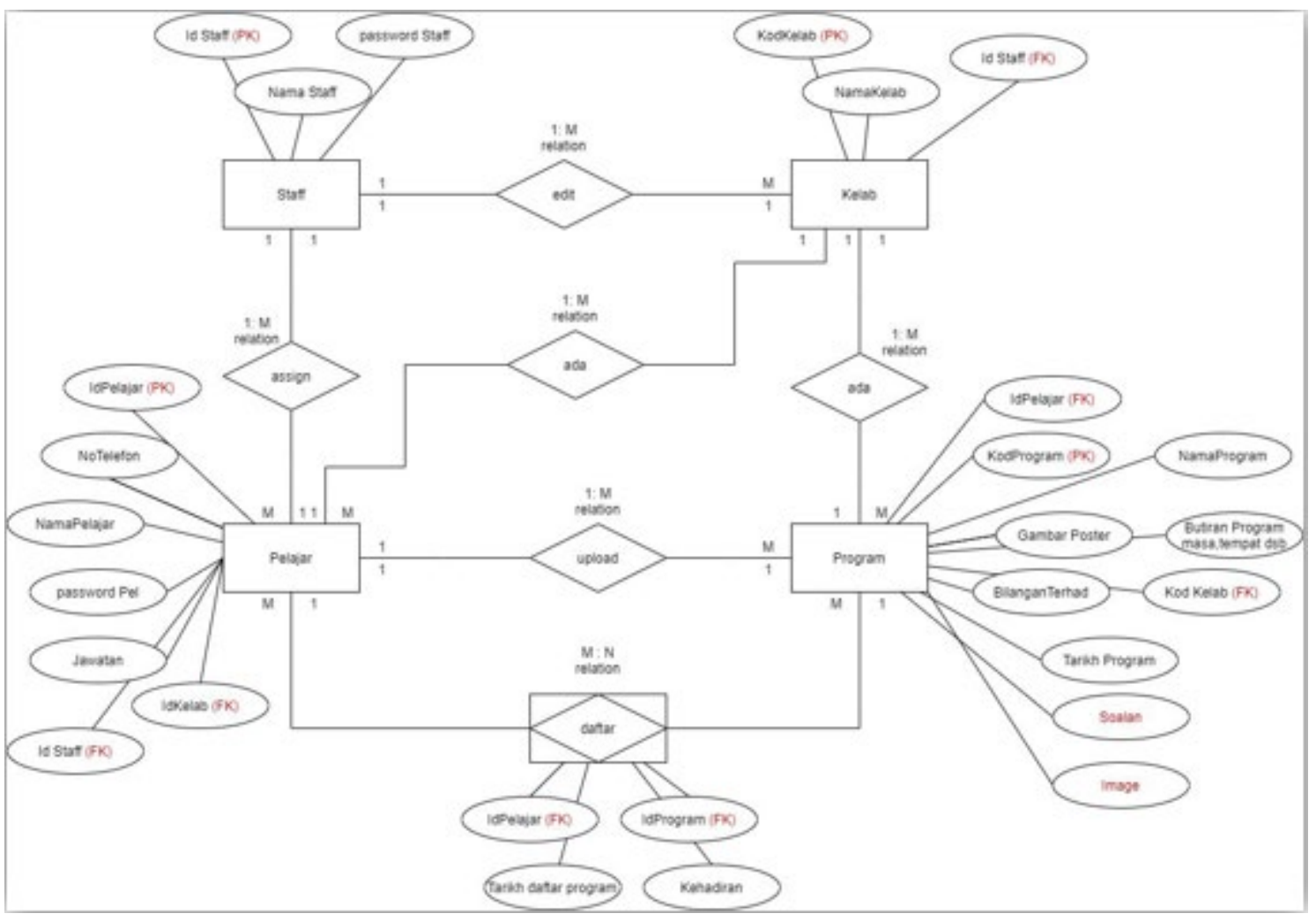

Rajah 6: Rajah Hubungan Entiti

Seterusnya, SPP direalisasikan pada fasa pembangunan dan implementasi. Asas kepada pembangunan sistem berasaskan web adalah bahasa pengaturcaraan Hypertext Markup Language (HTML), Cascading Style Sheets (CSS) dan Hypertext Preprocessor (PHP) [12]. Bagi memudahkan proses mengaturcara, penyuntingan dibuat menggunakan perisian Adobe Dreamweaver. Kerangka Bootstrap turut digunakan bagi mencapai hasrat mewujudkan sistem dengan reka bentuk web responsif. Selain itu, perisian XAMPP digunakan sebagai hos kepada SPP serta membina pangkalan data.

Akhir sekali adalah fasa penyelenggaraan, di mana apa-apa pepijat yang tidak dikenal pasti pada fasa sebelum ini dibaiki. Pada fasa ini juga, apa-apa perubahan atau permintaan ciri-ciri baru dari pengguna dipertimbangkan untuk dilaksanakan bagi meningkatkan keupayaan dan kecekapan SPP. Ini penting untuk memastikan penggunaan sistem dapat dioptimumkan.

\section{Hasil Dapatan dan Perbincangan}

Bagi mengukur keberkesanan serta kecekapan SPP, ujian penerimaan pengguna (user acceptance test) dan soal selidik telah dilaksanakan. Responden terdiri daripada 20 orang pelajar yang sedang menuntut di UTHM. Sebelum responden menjawab soal selidik melalui Google Form, mereka perlu terlebih dahulu melakukan ujian penerimaan melalui aplikasi Zoom. Aplikasi tersebut membolehkan responden mengawal antara muka SPP secara kawalan jauh. Selain itu, Zoom memudahkan responden berhubung secara terus dengan kami jika ada sebarang pertanyaan. Kaedah ini terpaksa digunakan, 
menggantikan kaedah secara bersemuka disebabkan kekangan-kekangan yang tidak dapat dielakkan. Pun begitu, rata-rata responden dapat menjalankan ujian penerimaan tanpa sebarang masalah.

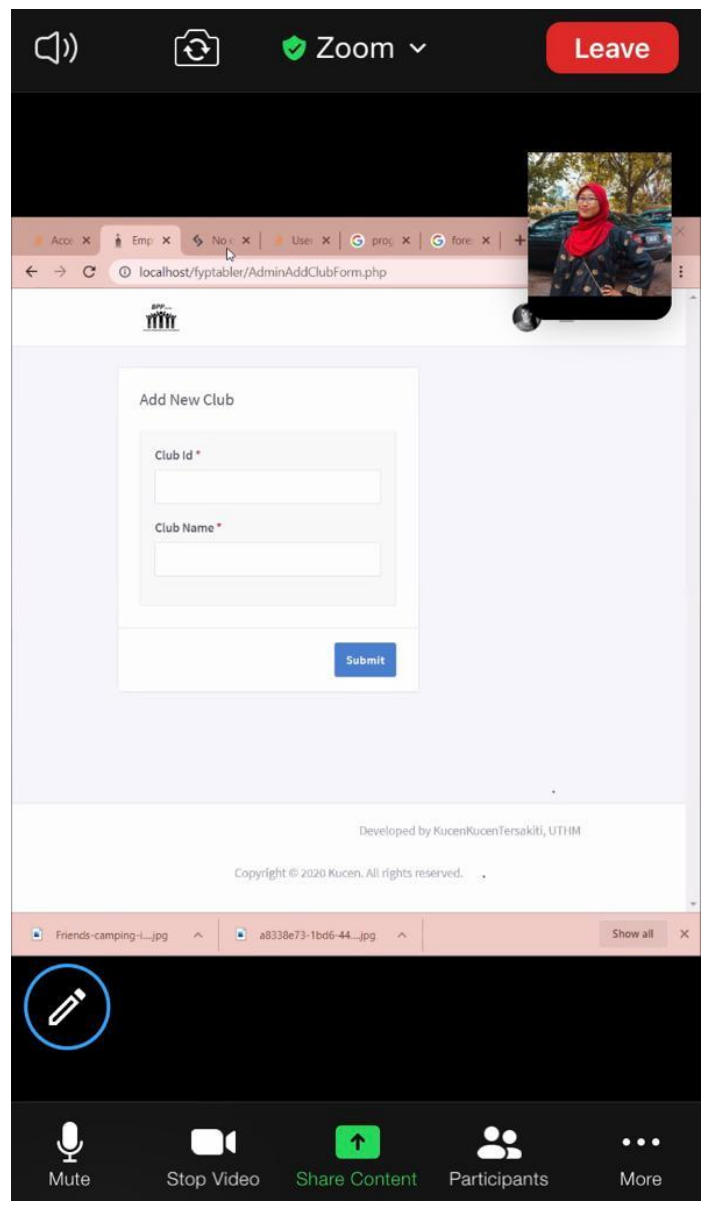

Rajah 7: Ujian Penerimaan Pengguna

Proses mengedar soal selidik serta mendapatkan semula kesemua maklum balas responden mengambil masa tiga hari. Soal selidik tersebut dibahagikan kepada tiga komponen. Komponen pertama melibatkan maklumat asas responden seperti nama penuh, nombor matrik, jantina dan peringkat pengajian. Komponen kedua melibatkan soal selidik sebelum SPP diperkenalkan, manakala komponen ketiga melibatkan soal selidik selepas menggunakan SPP.

Jadual 1: Sebelum Pengenalan SPP - Umum

\begin{tabular}{lll}
\hline \multirow{2}{*}{ Soalan } & \multicolumn{2}{l}{ Pilihan } \\
\cline { 2 - 3 } & Ya & Tidak \\
\hline 1. Adakah anda sentiasa mengetahui semua program yang dianjurkan di & $15 \%$ & $85 \%$ \\
$\quad$ UTHM? & & \\
2. Adakah anda pernah menyertai mana-mana program di UTHM? & $90 \%$ & $10 \%$ \\
3. Adakah anda pernah mengendalikan sesebuah program sebelum ini? & $40 \%$ & $60 \%$ \\
$\begin{array}{l}\text { 4. Adakah anda pernah tidak berkesempatan untuk menyertai program } \\
\quad \text { yang anda minati? }\end{array}$ & $100 \%$ & $0 \%$ \\
$\begin{array}{l}\text { 5. Adakah anda tidak berpuas hati jika tidak dapat menyertai mana-mana } \\
\text { program tersebut? }\end{array}$ & $80 \%$ & $20 \%$ \\
\hline
\end{tabular}


Merujuk kepada Jadual 1, rata-rata pelajar (85\%) tidak mengetahui program semasa yang dianjurkan di UTHM. Kebanyakan pelajar (90\%) dalam masa sama pernah menyertai program yang dianjurkan UTHM dan mereka tidak akan berpuas hati (80\%) jika mereka tidak dapat menyertai manamana program yang dianjurkan.

Jadual 2: Sebelum Pengenalan SPP - Sebab Tidak Berkesempatan Menyertai Program

\begin{tabular}{llll}
\hline \multirow{2}{*}{ Soalan } & \multicolumn{2}{l}{ Pilihan } & \\
\cline { 2 - 4 } & $\begin{array}{l}\text { Melebihi } \\
\text { Kuota }\end{array}$ & $\begin{array}{l}\text { Tidak } \\
\text { Mendapat } \\
\text { Maklumat }\end{array}$ & Lain-lain \\
\hline $\begin{array}{l}\text { 6. Jika anda jawab pernah pada soalan 4, mengapakah } \\
\text { anda tidak dapat menyertai program tersebut? }\end{array}$ & $35 \%$ & $85 \%$ & $10 \%$ \\
\hline
\end{tabular}

Soalan susulan kepada soalan 4 telah dikemukakan untuk mendapatkan maklumat mengenai sebab utama yang menjadi penghalang kepada pelajar dari menyertai program yang dianjurkan. Soalan ini merupakan soalan pelbagai pilihan. Hasil respons mendapati seramai $85 \%$ dari pelajar tidak mendapat maklumat program yang dianjurkan.

\section{Jadual 3: Sebelum Pengenalan SPP - Kaedah Mendapatkan Maklumat Program}

\begin{tabular}{lllll}
\hline & Pilihan & & \\
\cline { 2 - 5 } Soalan & Kawan & $\begin{array}{l}\text { Media Sosial } / \\
\text { Permesejan } \\
\text { Segera }\end{array}$ & Pensyarah $\begin{array}{l}\text { Lain- } \\
\text { lain }\end{array}$ \\
\hline $\begin{array}{l}\text { 7. Dari manakah anda mengetahui maklumat } \\
\text { mengenai sesuatu program? }\end{array}$ & $85 \%$ & $75 \%$ & $15 \%$ & $5 \%$ \\
\hline
\end{tabular}

Jadual 3 pula menunjukkan kaedah penerimaan maklumat program yang akan dianjurkan. Responden sekali lagi boleh memilih lebih dari satu pilihan untuk menjawab soalan ini. Kebanyakan mereka mendapatkan maklumat dari kawan, dan media sosial / aplikasi permesejan segera. Oleh itu, berdasarkan dapatan dari Jadual 1 hingga 3, kita boleh katakan kaedah penyampaian maklumat program melalui media sosial atau aplikasi permesejan segera kurang berkesan. Ini sekali gus menguatkan lagi keperluan untuk membangunkan SPP.

Jadual 4: Maklum Balas Penggunaan SPP

\begin{tabular}{llllll}
\hline \multirow{2}{*}{ Pernyataan } & \multicolumn{3}{l}{ Skala } & & \\
\cline { 2 - 6 } & 1 & 2 & 3 & 4 & 5 \\
\hline $\begin{array}{l}\text { 1. SPP dapat membantu anda dalam penyebaran program } \\
\text { yang akan dianjurkan. }\end{array}$ & $0 \%$ & $0 \%$ & $0 \%$ & $5 \%$ & $95 \%$ \\
$\begin{array}{l}\text { 2. Kemudahan merekod kehadiran di dalam SPP dapat } \\
\text { memudahkan kerja merekod kehadiran pelajar dan } \\
\text { hubungi pelajar yang menyertai program anda. }\end{array}$ & $0 \%$ & $0 \%$ & $0 \%$ & $30 \%$ & $70 \%$ \\
$\begin{array}{l}\text { 3. SPP memudahkan anda merujuk program yang telah } \\
\text { anda daftar. }\end{array}$ & $0 \%$ & $0 \%$ & $0 \%$ & $25 \%$ & $75 \%$ \\
$\begin{array}{l}\text { 4. SPP dapat digunakan dengan mudah. } \\
\text { S }\end{array}$ & $0 \%$ & $0 \%$ & $0 \%$ & $15 \%$ & $85 \%$
\end{tabular}


5. SPP membantu mengurangkan beban tugas AJK persatuan.

$$
\begin{array}{lllll}
0 \% & 0 \% & 0 \% & 25 \% & 75 \% \\
0 \% & 0 \% & 0 \% & 20 \% & 80 \%
\end{array}
$$

6. SPP memudahkan para pelajar menyertai program.

7. Reka bentuk antara muka SPP mudah difahami.

$0 \% \quad 0 \% \quad 0 \% \quad 45 \% \quad 55 \%$

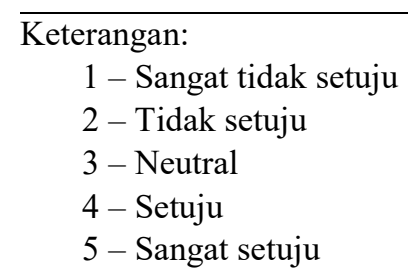

Berikutnya, bahagian terakhir soal selidik menyenaraikan pernyataan-pernyataan skala Likert. Responden diminta menyatakan sejauh mana mereka bersetuju atau tidak bersetuju dengan pernyataan yang dikemukakan. Hasil dapatan mendapati, kesemua responden memberi maklum balas positif (sekurang-kurangnya setuju) mengenai kemudahan menyebarkan maklumat program, kemudahan penggunaan dan reka bentuk antara muka SPP.

\section{Kesimpulan}

Ketiadaan satu platform khusus untuk menguar-uarkan serta mendapatkan maklumat program yang bakal dianjurkan di UTHM, menyebabkan para pelajar terpaksa bergantung kepada media sosial dan aplikasi permesejan segera. Hasil soal selidik mendapati kaedah ini kurang berkesan. Oleh itu, SPP dibangunkan bagi mengatasi masalah ini. Ujian penerimaan dan soal selidik kemudiannya diberikan kepada para responden bagi mendapatkan maklum balas mengenai SPP. Responden rata-rata memberi maklum balas positif terutama dalam aspek kemudahan menyebarkan maklumat program, kemudahan penggunaan dan reka bentuk antara muka SPP, sekali gus mengukuhkan pencapaian objektif projek. Pun begitu, masih ada ruang untuk melakukan penambahbaikan. Antara cadangan penambahbaikan yang dikenal pasti termasuklah memperkenalkan ciri pemberitahuan (notification) mengenai program yang bakal dilaksanakan dalam masa terdekat. Cadangan ini dilihat baik untuk SPP dalam mempertingkatkan lagi keberkesanannya.

\section{Penghargaan}

Penulis ingin merakamkan penghargaan yang tidak terhingga kepada Pusat Pengajian Diploma, Universiti Tun Hussein Onn Malaysia di atas sokongan yang diberikan. Penghargaan juga dirakamkan kepada semua yang terlibat secara langsung, mahupun tidak langsung dalam pembangunan projek ini.

\section{Rujukan}

[1] M. H. Baturay and M. Birtane, 'Responsive Web Design: A New Type of Design for Web-based Instructional Content', Procedia - Social and Behavioral Sciences, vol. 106, pp. 2275-2279, Dec. 2013, doi: 10.1016/j.sbspro.2013.12.259.

[2] V. Friedman, 'Responsive Web Design - What It Is And How To Use It', Smashing Magazine, Jan. 2011.

[3] B. S. Gardner, 'Responsive Web Design: Enriching the User Experience', Sigma Journal: Inside the Digital Ecosystem, vol. 11, no. 1, pp. 13-19, 2011.

[4] T. Black and M. Sharp, 'Eventbrite Review: Pricing, Pros, Cons \& Features', CompareCamp. https://comparecamp.com/eventbrite-review-pricing-pros-cons-features/ (accessed Aug. 10, 2020).

[5] S. Black et al., 'What is Eventbrite and How Does It Work?', TechBoomers, 2016. 
https://techboomers.com/t/what-is-eventbrite (accessed Aug. 10, 2020).

[6] Edmodo, 'What Information Do Notifications Show?', Edmodo Help Center, 2017. https://support.edmodo.com/hc/en-us/articles/205005104-What-Information-Do-NotificationsShow- (accessed Aug. 10, 2020).

[7] NTC Hosting, 'Adobe Dreamweaver', NTC Hosting Encyclopedia, 2020. https://www.ntchosting.com/encyclopedia/web-design/dreamweaver/ (accessed Aug. 10, 2020).

[8] J. Valade, PHP and MySQL Web Development All-in-One Desk Reference for Dummies. Indianapolis: Wiley Publishing, 2011.

[9] S. Reeves, 'XAMPP VS WAMP: Which Local Development Server is Better?', GoodCore, 2020. https://www.goodcore.co.uk/blog/xampp-vs-wamp/ (accessed Aug. 10, 2020).

[10] G. Shelly and H. Rosenblatt, Systems Analysis and Design, 11th ed. Boston: Cengage Learning, 2017.

[11] G. Sze Ming, 'Aplikasi Mudah Alih Pengurusan Ubat-ubatan Bersasakan Platform Android', Bachelor Thesis, Universiti Kebangsaan Malaysia, Bangi, 2014.

[12] Sagara Idea Lab, 'The Fundamentals of Front End and Back End Development', Medium, 2019. https://medium.com/@sagarajkt/the-fundamentals-of-front-end-and-back-end-development5973ac0910cf (accessed Aug. 10, 2020). 